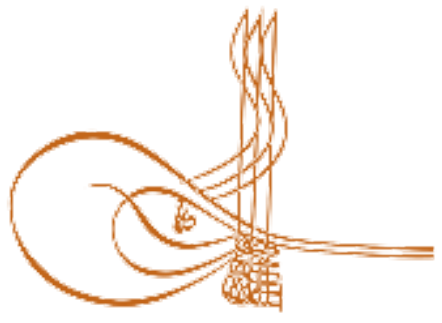

www.turkishstudies.net/education
Turkish Studies - Educational Sciences

eISSN: $2667-5609$

Research Article / Araştırma Makalesi

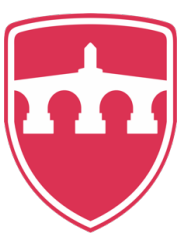

INTERNATIONAL

BALKAN

UNIVERSITY

Sponsored by IBU

\title{
İş Birlikli Problem Çözme Becerisine Yönelik Başarı Testi Geliştirme Çalışması ${ }^{*}$ \\ Developing An Achievement Test Towards Cooperative Problem Solving Skill
}

\author{
Gülçin Karakuş ${ }^{* *}$ - Gürbüz Ocak***
}

\begin{abstract}
The aim of this study is to develop a valid and reliable achievement test for evaluating collaborative problem solving skills of primary school fourth grade students. Today's education system predicts the environments in which students can communicate with each other socially, support each other and see the different perspectives and evaluate the effects of these perspectives. One of the methods to achieve this is a collaborative problem solving environment. For this purpose, based on the literature and needs analysis studies with teachers and students, gains for collaborative problem solving were determined and test questions were prepared in line with these gains. In order to determine the understandability of the test questions, the opinions of an expert who works in the field of cooperative learning and a language specialist working in the field of Turkish education were gathered. In the collaborative problem solving success test, the tables are presented to help understand which questions are suitable for which gains and which steps. The sample of this study was determined by typical sampling method which is one of the purposeful sampling methods. The application of the achievement test was carried out with 100 students studying in the 4th grade in 2018-2019 terms. Item analysis was performed for the items of the cooperative problem solving achievement test and the discrimination and difficulty index was calculated. By item analysis one item was removed from the test and the test, consisting of 21 items, has taken the final form. The item difficulty index and item discrimination index of whole test were 0.581 and 0.60 . The KR-20 value of the achievement test was calculated as 0.741 . As a result, an achievement test consisting of four-choice multiple-choice questions for cooperative problemsolving skills was developed.
\end{abstract}

Structured Abstract: Introduction: In this study it was aimed to develop a valid and reliable achievement test for evaluating cooperative problem solving skills of primary school fourth grade students. Today's education system suggests the environments in which students can communicate and support each other socially, see the

\footnotetext{
* Bu çalışma ilk yazarın İş Birlikli Problem Çözme Öğretim Programının Hazırlanması ve Uygulanması adlı doktora tezinden üretilmiştir. Bu çalışmadaki veriler 2018-2019 eğitim öğretim yılında toplanmıştır.

** Dr, Milli Eğitim Bakanlığ 1

PhD, Ministry of Education

ORCID 0000- 0002-0587-4079

karakusgulcin@gmail.com

**** Prof. Dr., Afyon Kocatepe Üniversitesi, Eğitim Fakültesi, Eğititim Bilimleri Bölümü

Prof. Dr., Afyon Kocatepe University, Faculty of Education, Department of Educational Sciences

ORCID 0000-0001-8568-0364

gocak@aku.edu.tr

Cite as/ Atıf: Karakuş, G. \& Ocak, G. (2020). İş Birlikli problem çözme becerisine yönelik başarı testi geliştirme çalışması, Turkish Studies - Education, 15(2), 983-997. https://dx.doi.org/10.29228/TurkishStudies.40151

Received/Geliş: 13 December/Aralık 2019

Accepted/Kabul: 13 April/Nisan 2020

Checked by plagiarism software

Copyright (C) INTAC LTD, Turkey

Published/Yayın: 30 April/Nisan 2020

CC BY-NC 4.0
} 
different perspectives and evaluate the effects of these perspectives. One of the methods to achieve this is a cooperative problem solving environment. Cooperative problem solving is viewed as necessary in educational settings. In cooperative problem solving, students work in groups and solve problems. Social support, seeking help, cohesion among the group members provide further development of problem solving skills (Ashman \& Gillies, 2003). Students should also be able to discuss the cooperative problem solving process in the educational environment. In this way, the student defends his view and evaluates the views of others (Heller \& Hollabaugh, 2001). Accordingly it is important to evaluate students' cooperative problem solving skills for the improvement of problem solving and cooperative working.

\section{Literature Review}

Cooperative problem solving is a powerful source of motivation (Carlon, Rubin \& Mogan, 2004) as well as all its positive effects. In this process the student realizes his/her own deficiencies with the feedback given after a while, and over time, the problem-solving skill develops and the probability of repetition of errors decreases (Heller \& Heller, 2001). Literature review indicates that there exist studies involving rubrics and evaluation for cooperative learning environment (Avcı Yücel, 2013; Law \& Wong, 2003), for peer assessment in cooperative environment (Gömleksiz \& Koç, 2011; Yurdabakan \& Olğin, 2011), for evaluation of the group (Önder, 2012; Griffin, 2017; Quarstein \& Peterson, 2001), for evaluation of cooperative learning in language class (Ghaith, 2002; Szostek, 1994), for cooperative problem solving in the computer environment (Hao, Liu, Davier \& Kyllonen, 2015), for cooperative problem solving in the technology-supported environment (Nouri, Anna, Fors \& Selander, 2017). However, it is seen in the literature that there is no study that includes an achievement test for measuring cooperative problem solving skills. In this context, this study, which aims to develop cooperative problem solving success test for fourth grade students, is considered to be important and will contribute to the literature.

\section{Method}

In this study, survey method, one of the quantitative research methods, was used. This refers to collecting data from a sample group systematically (Leeuw, Hox \& Dillman, 2012). 100 students consists of the study group of this study. 61 of the students are male and 39 are female.

\section{Findings and Discussion}

Firstly, the objectives in order to measure cooperative problem solving skills were determined. In addition, students' and teachers' opinions about cooperative problem solving skills were obtained by making study for the needs analysis. Eight open-ended questions about cooperative problem solving were asked to 15 students studying in the fourth grade. Eight open-ended questions were asked to the eight teachers consisting of a primary school teacher, English teacher, Turkish teacher, counselor teacher, and visual arts teacher, science teacher, social studies teacher and physical education teacher, and their opinions were evaluated within the scope of the study. In addition, a success test was designed on the basis of evaluation criteria prepared by OECD (2013) for use in the PISA (2015) exam. In line with the cooperative problem solving achievement test pilot application, with the discrimination and item difficulty indices of each item in the upper and lower groups were determined. Item discrimination index is considered to be quite good at 0.40 and above, and reasonably good at 0.30-0.39. It is considered to be developable at $0.20-0.29$, and 0.19 or less is considered as weak (to be removed) (Taib \& Yusoff, 2014; Rahim, 2010; Ebel andFrisbie, 1991; Escudero, Reyna \& Morales, 2000). According to these values, items 1, 2, 3, 4, 7, 8, 9, 10, 11, 13, 14, 15, 16, 17, 18, 19, 20, 22 are quite good; items 5, 6, 21 are good, and item 12 is lower than 0.09 is weak. In this context, the item was excluded from the test. The average difficulty of the test was 0.581 and the average discrimination was found as 0.60 . Difficulty is determined as at a medium level. (Escudero, Reyna and Morales, 2000; Quaigrain and Arhin, 2017; Odukoya, Adekeye, Igbinoba and Afolabi, 2018; Lane, Raymond and Haladyna, 2015). The reliability coefficient of the test between $0.60 \leq \alpha<0.80$ (Christiansen, 2014) indicates that the test is reliable (Gliem and Gliem, 2003; Russek, 2004; Vansickle, 2015; Flateby, 2014). In this context, KR20 value was found as 0.741 and KR21 was found as 0.720 in cooperative problem solving achievement test so the study can be viewed as reliable.

\section{Conclusion and Suggestions}

In this study, firstly objectives were determined for scope validity and these objectives were presented to the expert opinion. Then, test questions were prepared in accordance with the measurement of these 
objectives. The application of the achievement test was carried out with 100 students studying in the 4 th grade. Item analysis was performed for the items of the cooperative problem solving achievement test and the discrimination and difficulty index was calculated. The average difficulty of the test was 0.581 and the average discrimination was 0.60 and. KR20 value of the test was determined as 0.741 . As a result, an achievement test consisting of multiple choice questions for cooperative problem solving skills was developed. In the planning and preparation process, the steps of the success test were determined clearly and each stage was carefully stated and reviewed. The aim is to identify students who have little progress or do not have sufficient skills within a certain context and can help eliminate deficiencies (Katz and Slomka, 2000).

Evaluating students with an achievement test has some positive effects. One of them is giving equal chance for evaluation. Ensuring equal participation of all members of the group in the collaborative problemsolving process is a key element (Cohen, 1994; Stahl, 1994). Moreover the equal participation should also be evaluated in the same way. Therefore, instead of a group work, evaluating the group members individually by using achievement test can provide a successful result.

Another positive result of evaluating the students individually with the success test in the collaborative problem solving process is to ensure that each student in the group is satisfied with their individual choice. In the evaluation made as a whole, the group member may remain in a situation that he / she does not approve of in order to adapt to the group friends or to comply with the decision of the majority, even if he is not satisfied with his own. However, it is aimed to reach a result that will satisfy all group members on the basis of collaborative problem solving (Wooldridge \& Jennings, 1999). If the student individually chooses the appropriate option, all group members will be satisfied with the results they have chosen and will be evaluated accordingly.

Keywords: Education, Cooperative Learning, Problem Solving Cooperative Problem Solving, Achievement Test.

Öz: Bu çalışmanın amacı ilkokul dördüncü sınıf öğrencileri için, iş birlikli problem çözme becerisini değerlendirmeye yönelik geçerli ve güvenilir bir başarı testi geliştirmektir. Günümüz eğitim sistemi öğrencilerin hem sosyal olarak birbirleri ile iletişim kuracakları, birbirlerini destekleyecekleri hem de farklı bakış açılarını görüp, bu bakış açılarının etkilerini değerlendirebilecekleri ortamları öngörmektedir. Bunu sağlayacak yöntemlerden biri iş birlikli problem çözme ortamıdır. Bu amaçla alan yazından ve öğretmenler ve öğrencilerle yapılan ihtiyaç analizi çalışmalarından yola çıkılarak iş birlikli problem çözmeye yönelik kazanımlar belirlenmiş ve bu kazanımlarla uyumlu test soruları hazırlanmıştır. Test sorularının anlaşılabilirliğinin belirlenmesi için iş birlikli öğrenme alanında çalışmaları olan bir uzmanın ve Türkçe eğitimi alanında çalışan bir dil uzmanının görüşleri alınmıştır. Çalışmada hazırlanan tablolar ile iş birlikli problem çözme başarı testinde hangi soruların hangi kazanımlara ve hangi basamaklara uygun olduğunun anlaşılması hedeflenmiştir. Çalışmanın örneklemi amaçlı örnekleme yöntemlerinden tipik örnekleme ile belirlenmiştir. Başarı testinin uygulaması 2018-2019 eğitim öğretim yılında 4. sınıfta öğrenim gören 100 öğrenci ile gerçekleştirilmiştir. İşbirlikli problem çözme başarı testinin maddeleri için madde analizi yapılmış ve ayırt edicilik ve güçlük indeksi hesaplanmıştır. Madde analizi ile bir madde testten çıkarılmış ve 21 maddeden oluşan test son halini almıştır. Testin ortalama güçlüğü 0.581 ortalama ayırt ediciliği 0.60 ve olarak belirlenmiş̧ir. Testin KR20 değeri 0,741 olarak tespit edilmiştir. Sonuç olarak iş birlikli problem çözme becerisine yönelik dört seçenekli çoktan seçmeli sorulardan oluşan bir başarı testi geliştirilmiştir.

Anahtar Kelimeler: Eğitim, İş Birlikli Öğrenme, Problem Çözme, İş Birlikli Problem Çözme, Başarı Testi.

\section{Giriş}

Dünya çapında yaşanan hızlı teknolojik gelişmeler eğitim ortamlarını da olumlu yönlerde etkilemekte, eğitim öğretim sürecini daha kolay uygulanabilir ve daha eğlenceli bir yapıya dönüştürmektedir. Ancak her ne kadar bu imkânların sağladığg kolaylıklar olsa da öğrencilerin temelde sahip olması gereken becerilerin de öğretim programlarında yer alması gerekmektedir. Eğitim ortamının sunduğu olanaklar öğrencinin hayat boyu kullanması gereken becerilerin kazanılması için tek başına kullanıldığı takdirde yetersiz kalabilir. Temel amaç eğitimin hedeflerinin 
eğitim ortamından sonra da kullanılabilecek şekilde öğretilmesi olduğu takdirde eğitimin hayat boyu öğrenme boyutuna geçiş sağlanabilir.

Günümüz eğitim sistemi öğrencilerin hem sosyal olarak birbirleri ile iletişim kuracakları, birbirlerini destekleyecekleri hem de farklı bakış açılarını görüp, bu bakış açılarının etkilerini değerlendirebilecekleri ortamları öngörmektedir. Bunu sağlayacak yöntem ise iş birlikli problem çözme ortamıdır. İşbirlikli problem çözmenin iki temel unsuru vardır; iş birlikli öğrenme ve problem çözme. İşbirlikli problem çözme iş birlikli öğrenmenin ve problem çözmenin birlikte uygulanmasını ifade etmektedir. İş birlikli öğrenme öğrencilerin verilen görevi diğer grup üyelerinin de çaba göstermesi ile tamamladıkları öğrenme ortamlarıdır (Deutsch, 1962). Watson (1992) iş birliğine dayalı öğrenmeyi iki veya daha fazla öğrencinin hevesle beraber çalışması ve belirli bir görevi tamamlaması olarak tanımlamaktadır. Bejanaro (1987) ise iş birlikli öğrenmeyi, öğrencilerin gruplar halinde yapılandırılmış aktiviteleri tamamlamak amacıyla, bireysel sorumlulukla çalışmaları ve grup halinde değerlendirilmeleri olarak nitelendirilmektedir. İş birlikli öğrenme yönteminin litertürde pek çok olumlu etkisi olduğu belirtilmektedir. Örneğin, Quin, Johnson ve Johnson (1995) iş birlikli öğrenmenin üst düzey problem çözme becerisini geliştirdiğini ifade etmektedir. Bunun nedeni, öğrencilerin bu süreçte bilgi alışverişinde bulunması, problemi çözmek için çeşitli stratejiler oluşturmaları, ifade edilen problemi bilişsel bir yapıda zihinlerinde canlandırmaları olabilir.

İş birlikli öğrenme ortamı, öğrencinin problem çözme becerisini geliştirir. İş birliği yaparak problem çözen öğrencilerin bireysel olarak çalışan ya da rekabet ortamında olan öğrencilere göre problem çözme becerileri daha fazla gelişir. Bu durum öğrencilerin problem çözme sürecinde yaratıcılıklarının da gelişmesini sağlar. Yaratıcı problem çözme becerisi yeni veya farklı bir görüşü kabul ettirme çabası ile gelişmektedir. Bunun nedeni, öğrencinin farklı bir görüşü sunarken ya da savunurken yaratıcılığını kullanmasıdır (Johnson, Skon ve Johnson, 1980). Problem çözmenin eğitimde etkili olmasının nedeni öğrencinin bu süreçte farklı çözüm yollarını görmesi, bu yolları karşılaştırması ve hangisinin daha etkili olduğuna karar vermesidir (Johnston, Johnston ve Markle, 1986).

Ayrıca problem çözme becerisi gelişmeyen bireyler hayatta başarılı olmakta zorlanabilirler. Bunun nedeni karşılaştığı probleme çözüm bulamamanın verdiği umutsuzluk duygusu olabilir. Ya da birey tek bir çözüm yolu bulduğunda bu çözüm işe yaramazsa, diğer çözüm yollarını da düşünebilmelidir. Başkalarından çözüm için yardım talep edebileceğinin farkında olmamak, bu destekten mahrum olmak önemli bir eksiklik olacaktır. Bu nedenle eğitimcilerin, öğrencilerin sorun çözme becerilerini desteklemeleri ve bu yönde eğitimsel uygulamalar yapmaları gerekebilir. Problem çözme becerisinin geliştirilmesi yaşam boyu öğrenmeyi destekleyebilir. Problem çözme becerisi birlikte çalışma ile geliştirilebilir. İş birlikli problem çözme bu bağlamda uygun bir araç olabilir. Bu nedenle iş birlikli problem çözme, öğretim programlarında yer alması yararlı olabilir. Ayrıca iş birlikli problem çözme ile öğrenci fikir alışverişinde bulunmayı, özgüveni ve saygıyı öğrenir. Bu sayede öğrencinin derse katılımı, öğrenimi artar ve hatırlaması kolaylaşabilir.

Eğitim ortamında iş birlikli problem çözme sürecinde öğrencilerin tartışabilmeleri de gerekmektedir. Öğrenci bu sayede kendi görüşünü savunur ve başkalarının görüşlerini değerlendirir (Heller ve Hollabaugh, 2001). İş birlikli problem çözme ile Vygotsky ve Piaget'nin öğrencilerin nasıl öğrendiklerine dair vurguladıkları görüşleri de desteklenir. İş birlikli problem çözmede öğrenciler birbirlerinin öğrenimini destekler, birbirleriyle iletişim kurar, fikir alışverişinde bulunur, kendi gayretlerinin farkına varır, birlikte daha çok çalışmak ve daha çok problem çözme aktivitesine katılmak isterler. Sosyal destek, yardım arayışı, grup üyeleri arasındaki uyum, problem çözme becerisinin daha da gelişmesini sağlar (Ashman ve Gillies, 2003).

İş birlikli problem çözme, tüm bu olumlu etkilerinin yanı sıra aynı zamanda da güçlü bir motivasyon kaynağıdır (Carlon, Rubin ve Mogan, 2004) ve öğrenciyi yönlendirici destek sağlar. Bu desteği, kavramların öğrenilmesi ve sürecin özümsenmesi kapsamında grup üyeleri oluşturur. Diğer 
grup bireyleri öğrencinin kendi kendini izlemesine yardımcı olur. Öğrenci, bir süre sonra verilen dönütlerle kendi eksikliklerinin farkına varır ve zamanla iş birlikli problem çözme becerisi gelişir ve hataların tekrarlanma olasılığı azalır (Heller ve Heller, 2001).

Literatürde iş birlikli problem çözmenin olumlu etkileri olduğu ifade edilmektedir. Örneğin iş birlikli problem çözme ile öğrencinin verilen problem durumuna uygun hipotez kurma becerisi gelişir (Yarrow ve Topping, 2001). Bilgiyi sosyal etkileşim ile yapılandırmasının sonucu olarak bilgi daha kalıcı olur (Tudge, Winterhoff ve Hogan, 1996), iş birlikli problem çözen öğrenci bireysel çalışan öğrencilere göre akademik olarak daha başarılı olur (Ramani ve Brownell, 2014) ve öğrencilerin başarı güdüsü artar (Gök ve Silay, 2009). Bununla birlikte Gillies ve Haynes (2010) ise iş birlikli problem çözmenin, sınıfta öğrencinin konuşma süresini arttırdığı için öğrenciler arasında iletişimi de arttıracağını belirtmektedir. İş birlikli problem çözme becerisinin değerlendirilmesi ile ilgili yapılan literatür çalışmalarında iş birlikli öğrenme ortamına yönelik rubrik ile değerlendirme içeren çalışmalara (Avc1 Yücel, 2013; Law ve Wong, 2003), iş birlikli ortamda akran değerlendirmeye yönelik çalışmalara (Gömleksiz ve Koç, 2011; Yurdabakan ve Olğun, 2011), grubu değerlendirmeye yönelik çalışmalara (Önder, 2012), iş birlikli grupları belirli kriterlere göre değerlendirmeye yönelik çalışmalara (Griffin, 2017; Quarstein ve Peterson, 2001) dil sınıfında iş birlikli öğrenmeyi değerlendirmeye yönelik çalışmalara (Ghaith, 2002; Szostek, 1994), bilgisayar ortamında iş birlikli problem çözmeye yönelik değerlendirme içeren çalışmalara (Hao, Liu, Davier ve Kyllonen, 2015), teknoloji destekli ortamda iş birlikli problem çözmeyi iletişim kapsamında değerlendiren çalışmalara (Nouri, Anna, Fors ve Selander, 2017) rastlanılmaktadır. Ancak literatürde iş birlikli problem çözme becerisini ölçemeye yönelik başarı testi içeren bir çalışma olmadığı görülmektedir. Bu bağlamda dördüncü sınıf öğrencileri için iș birlikli problem çözme başarı testi geliştirmeyi amaçlayan bu çalışmanın önemli olduğu ve alan yazına katkı sağlayacağı düşünülmektedir.

\section{Yöntem}

Bu çalışmada nicel araştırma yöntemlerinden tarama modeli kullanılmıştır. Tarama modeli belirli bir grup veya kategoride ne düşünüldüğünün anlaşılması için bir örneklem grubundan veri toplanılmasını ifade etmektedir. Tarama modeli sistematik, organize ve nicel olarak geniş bir evrenden nispeten küçük bir örneklem aracılığıyla veri toplanan bir modeldir. (Leeuw, Hox ve Dillman, 2012).

\section{Çalıșma Grubu}

$\mathrm{Bu}$ çalışmanın çalışma grubunu 100 kişilik 4. sınıf öğrencisi oluşturmaktadır. Öğrencilerin 61'i erkek, 39'u ise kız öğrenciden oluşmaktadır. Çalışmaya katılan 13 öğrenci ailenin tek çocuğu iken, 23 öğrencinin bir kardeşi vardır, 38 öğrencinin ise iki kardeşi vardır, 26 öğrencinin ise üç ve üzeri kardeşi vardır. Çalışma grubu amaçlı örnekleme yöntemi ile belirlenmiştir. Amaçlı örnekleme bilgi kaynağı açısından zengin örneklem üzerinde derinlemesine inceleme yapmak için tercih edilmektedir. Amaçlı örneklemede araştırmacı amaca yönelik daha detaylı bilgi edinebilmektedir (Patton, 1990). Çalışmada amaçlı örnekleme yöntemlerinden tipik örnekleme yöntemi kullanılmıştır. Tipik durum örneklemesinde tipik, normal, siradan bir birim (birey, durum, olay veya yer) örneklem olarak tercih edilir (Şahin ve Karakuş, 2019). Tipik örnekleme yönteminin tercih edilmesinin nedeni iş birlikli öğrenme etkinlikleri ve problem çözme çalışmalarına katılan tipik dördüncü sınıf öğrencilerine yönelik bir çalışma olmasıdır. Çalışma grubunun 4. Sınıf öğrencileri olarak belirlenmesinin nedeni ise, öğrencilerin iş birlikli problem çözme becerisine erken yaşta kazanmalarının ilerde akademik yaşamlarında bu beceriyi kullanabilmelerinin önemli olarak değerlendirilmesi görüşüne dayanmaktadır. Ayrıca çalışma 2018-2019 eğitim öğretim yılında Afyonkarahisar merkezinde farklı sosyoekonomik ve farklı akademik özellikleri olan öğrencilerin öğrenim gördüğü bir ilkokulda gerçekleştirilmiştir. 


\section{Başarı Testinin Geliştirilmesi}

Çalışmada ilk olarak iş birlikli problem çözme becerisinin ölçülmesine yönelik olarak ölçülecek amaçlar belirlenmiştir. Bu süreçte literatürde yer alan çalışmalar (Avcı Yücel, 2013; Ghaith, 2002; Gömleksiz ve Koç, 2011; Griffin, 2017; Hao, Liu, Davier ve Kyllonen, 2015; Law ve Wong, 2003; Nouri, Anna, Fors ve Selander, 2017; Önder, 2012; Quarstein ve Peterson, 2001; Szostek, 1994; Yurdabakan ve Olğun, 2011) incelenmiştir. Ayrıca ihtiyaç analizi yapılarak iş birlikli problem çözme becerisine yönelik öğrenci ve öğretmen görüşleri alınarak başarı testi için süreçte incelenerek değerlendirilmiştir. İhtiyaç analizi için öğrenci ve öğretmen görüşleri alınmıştır. Dördüncü sınıfta öğrenim gören 15 öğrenciye iş birlikli problem çözme ile ilgili sekiz açık uçlu soru sorulmuştur. Sınıf Öğretmeni, İngilizce Öğretmeni, Türkçe Öğretmeni, Rehber Öğretmen ve Görsel Sanatlar, Fen Bilimleri, Sosyal Bilgiler ve Beden Eğitimi Öğretmeninden oluşan sekiz kişilik öğretmen grubuna ise yedi açı uçlu soru sorulmuş ve öğretmen ve öğrenci görüşleri çalışma kapsamında değerlendirilmiştir. Ayrıca OECD (2013) tarafından PISA (2015) sınavında kullanılması amacıyla hazırlanan değerlendirme ölçütleri temelinde başarı testi tasarlanmıştır.

Tablo 1: OECD (2013) Tarafından Hazırlanan PISA (2015) Temel Değerlendirme Ölçütleri

\begin{tabular}{|c|c|c|c|}
\hline & $\begin{array}{c}\text { 1. Ortak Bir Anlayış } \\
\text { Kurma, Anlayışı Koruma }\end{array}$ & $\begin{array}{l}\text { 2. Problemin Çözümü İçin } \\
\text { Uygun Adımı Atma }\end{array}$ & $\begin{array}{c}\text { 3.Takım Organizasyonu Kurmak } \\
\text { ve Bunu Korumak }\end{array}$ \\
\hline $\begin{array}{l}\text { (A) Keşfetme ve } \\
\text { Anlama }\end{array}$ & $\begin{array}{c}\text { Grup üyelerinin bakış } \\
\text { açılarını ve yeteneklerini } \\
\text { fark etme }\end{array}$ & $\begin{array}{l}\text { Problemin çözümü için } \\
\text { hedefler doğrultusunda iş } \\
\text { birlikli iletişim yapısını } \\
\text { belirleme }\end{array}$ & $\begin{array}{l}\text { Problemin çözümü için üyelerin } \\
\text { rollerini anlama }\end{array}$ \\
\hline $\begin{array}{l}\text { (B) Temsil etme } \\
\text { ve Formülleme }\end{array}$ & $\begin{array}{l}\text { Problemin ne demek } \\
\text { istediğini görüşme ve } \\
\text { ortak bir anlayış oluşturma }\end{array}$ & $\begin{array}{c}\text { Tamamlanacak olan görevin } \\
\text { tanımının yapılması }\end{array}$ & Rollerin tanımının yapılması \\
\hline $\begin{array}{l}\text { (C) Planlama ve } \\
\text { Planı Uygulama }\end{array}$ & $\begin{array}{c}\text { Yapılan çalışmalar } \\
\text { hakkında grup üyeleri ile } \\
\text { iletişime geçme }\end{array}$ & Planı harekete geçirme & $\begin{array}{c}\text { Kurallara uyulmasi (grup } \\
\text { üyelerini görevlerini yerine } \\
\text { getirmeleri konusunda teşvik } \\
\text { etme }\end{array}$ \\
\hline $\begin{array}{l}\text { (D) İzleme ve } \\
\text { Yansitma }\end{array}$ & $\begin{array}{l}\text { İzleme ve ortak anlayışı } \\
\text { sağlamayı çalışma }\end{array}$ & $\begin{array}{c}\text { Yapılanların sonuçlarını izleme } \\
\text { ve problem çözmedeki başarıyı } \\
\text { değerlendirme }\end{array}$ & $\begin{array}{c}\text { İzleme, geri dönüt sağlama, takım } \\
\text { organizasyonuna ve rollerine } \\
\text { uyum sağlama }\end{array}$ \\
\hline
\end{tabular}

Tablo 1 incelendiğinde ölçütlerin bazıları şu şekilde olduğu görülmektedir: iş birlikli problem çözme becerisine sahip bir öğrenci grup üyelerinin bakış açılarını ve yeteneklerini fark eder, hedefler doğrultusunda iş birlikli iletişim yapısını belirler, problemin çözümü için üyelerin rollerini anlar, problemin ne demek istediğini görüşür ve ortak bir anlayış oluşturur. Bu ölçütlerden hareketle iş birlikli problem çözme becerisinin kazanımları belirlenmiştir. Belirlenen kazanımlara uygun olarak hazırlanan 22 soruluk, dörder seçenekli, taslak test maddeleri 13 kişilik öğrenci grubuna pilot uygulama yapılarak form denenmiştir. Bu uygulama sırasında Ölüdeniz ve Akvaryum ile ilgili problem durumları öğrenciler için anlaşılmayı zorlaştıracak şekilde uzun olduğu görüşünün belirtilmesi nedeniyle, anlam bozulmayacak şekilde bu sorular kısaltılmıştır. Verilen senaryolarda öğrencilere senaryo ile ilgili uzun bilgiler verildiği ve öğrencilerin yaş grubunun özellikleri dikkate alındığında odaklanama sorunu yaşadıkları, daha kolay anlayacakları dikkate alınarak senaryolarda daha kısa açıklamalara yer verilmiştir. Ayrıca logo kelimesinin öğrenciler tarafından anlaşılmasında zorluk çekildiği belirlenmiş ve logo kelimesi öğrenciler için daha anlaşılır olan sembol kelimesi ile değiştirilmiştir. Test sorularının anlaşılabilirliğinin belirlenmesi için iş birlikli öğrenme alanında bir uzman ve Türkçe eğitimi alanında bir dil uzmanının görüşleri alınmıştır. Gerekli düzeltmeler yapıldıktan sonra ise başarı testinin asıl uygulaması 100 kişilik gruba uygulanmıştır. 
Tablo 2: OECD’nin (2013) İşbirlikli Problem Çözme Kriterlerine Göre Başarı Testi Sorularının Dağılımı

\begin{tabular}{|c|c|}
\hline Kriter & $\begin{array}{c}\text { Soru } \\
\text { Maddeleri }\end{array}$ \\
\hline $\begin{array}{c}\text { Grup üyelerinin bakış açılarını ve yeteneklerini keşfeder ve grup üyeleri ile eylemler hakkında } \\
\text { iletişim kurar. }\end{array}$ & $1-6-13-14-18$ \\
\hline $\begin{array}{l}\text { Problem çözmek için bir strateji geliştirir. } \\
\text { Ortak anlayış oluşturur ve sürdürür. }\end{array}$ & $\begin{array}{c}2 \\
2-13\end{array}$ \\
\hline Grup üyeleri ile problem çözmede iş birliğine dayalı etkileşim kurar. & $3-5-10-19-22$ \\
\hline Problem çözmek için uygun bir strateji belirler. & 4-13-17 \\
\hline Problem çözme stratejisini uygular ve değerlendirir. & $5-9$ \\
\hline Grup çalışması sürecini izler ve yansıtır. & $6-10-17$ \\
\hline Grup üyeleri ile organizasyon oluşturur ve sürdürür. & 7 \\
\hline Uygun problem çözme stratejisini belirler. & 8 \\
\hline Grup üyeleri ile ortak anlayışın oluşturur ve paylaşır. & $9-19-21$ \\
\hline Grup organizasyonunda rolleri belirler. & $9-20$ \\
\hline Grup organizasyonu kurar ve sürdürür. & $10-13-16-12$ \\
\hline $\begin{array}{c}\text { Grup içersinde problem çözme stratejilerini uygular, eylemlerin sonuçlarını izler ve problemi } \\
\text { çözmede grup başarısını değerlendirir. }\end{array}$ & $11-19$ \\
\hline Problemi anlar. & 12 \\
\hline İzler, geri bildirim sağlar ve grup organizasyonunu ve rollerini uyarlar. & $15-16-17$ \\
\hline Problemi anlamaya yönelik grup içi tartışmalar oluşturur. & 18 \\
\hline Grup üyelerinin görevlerini takip eder. & 19 \\
\hline Problemi çözmek için iş birlikçi etkileşim kurar. & 20 \\
\hline
\end{tabular}

Tablo 2'de görüldüğü gibi, iş birlikli problem çözme başarı testinde yer alan maddeler aynı anda birden fazla ölçüte uyum sağlamaktadır. Bu durumun nedeni OECD (2013) ölçütlerinde de belirtildiği üzere iş birlikli problem çözme becerisinin iki basamaklı bir yapıya sahip olması ve öğrencilerin hem iş birlikli çalışma aşamaları hem de problem çözme aşamaları kapsamında birlikte değerlendirilmesidir. Örneğin, öğrencinin süreçte hem grup arkadaşını izlemesi, hem ona dönüt vermesi, hem de takım organizasyonunu sürdürmesi gerekmektedir. İş birlikli problem çözme sürecinde, öğrencinin başarı testine verdiği cevabın grup arkadaşının fikrini değerlendirmesi ve kendi fikri ile birlikte grubun başarısına katkı sağlayabilecek bir sentez oluşturması gerekebilir. Bu bağlamda öğrenci verdiği bir cevapta iş birlikli çalışma ve problem çözme becerisine yönelik karar vereceği için bilişsel seviyede de iki yönlü bir sonuca ulaşılmaktadır.

Başarı testi hazırlanırken PISA (2015) için OECD (2013) tarafından belirlenen kriterler kapsamında hazırlanan sorular Bloom taksonomisine göre sınıflandırılmış ve Tablo 3'de sunulmuştur. 


\begin{tabular}{cc}
\hline Tablo 3: Soru Maddelerinin Bloom Taksonomisine Göre Dağllimı \\
\hline Soru & Bilişsel Seviye \\
\hline $1-14-18$ & Kavrama- Uygulama \\
13 & Kavrama \\
$2-13$ & Uygulama \\
$3-5-10-19-22$ & Kavrama-Uygulama \\
$4-13-17$ & Uygulama \\
$5-9$ & Değerlendirme \\
$6-13$ & Kavrama-Değerlendirme \\
$6-10-17$ & Değerlendirme \\
7 & Değerlendirme \\
8 & Uygulama-Değerlendirme \\
$9-19-21$ & Değerlendirme-Sentez \\
$9-20$ & Bilgi \\
$10-13-16-12$ & Uygulama- Değerlendirme \\
$11-19$ & Uygulama- Değerlendirme- Sentez \\
$15-16-17$ & Analiz-Değerlendirme \\
18 & Analiz-Uygulama \\
19 & Değerlendirme \\
20 & Bilgi- Kavrama \\
\hline
\end{tabular}

Soru maddelerinin hangi bilişsel seviyeye uygun olduğunu gösteren Tablo 3, hazırlanan ölçme aracının hedeflerini, yönergelerini, etkinliklerini ve değerlendirmelerinin düzenlenmesine yardımcı bir plan olarak görülebilir. Bu bağlamda Tablo 3. de sunulan bilgiler iş birlikli problem çözme başarı testinde hangi soruların hangi kazanımlara ve hangi basamaklara uygun olduğunun anlaşılmasına yardımcı olduğu görülmektedir. Bu nedenle sorular birden fazla basamağa denk gelmektedir. İş birlikli problem çözme süreci çok boyutlu olduğu için öğrencinin verdiği bir cevapla hem analiz yapması hem de değerlendirme yapması söz konusu olabilmektedir.

İş birlikli problem çözme başarı testinde yer alan örnek maddeler aşağıda sunulmuştur;

14. Soru: Murat: “Biliyor musunuz ben daha önce de bir akvaryum tasarlamıştım ”, bu durumda siz seçeneklerde verilen ifadelerden hangisini söylersiniz?

a) "Hadi akvaryumla ilgilenelim."

b) "Akvaryum için şimdi ne yapmalıyız sizce?"

c) "Tamam, ama bu bizim için bir şey ifade etmiyor şu anda."

d) "Öyle mi anlatsana Murat ne yapmıştın, bize fikir verebilir?"

Bu soruda iş birlikli problem çözme sürecinde öğrencinin "Grup üyelerinin bakış açılarını ve yeteneklerini keşfeder ve grup üyeleri ile eylemler hakkında iletişim kurar" kriterine uygun olarak arkadaşının daha önce ne yaptığına yönelik bakış açısını ve yeteneğini keşfetmesi ve sürece yönelik iletişim kurması beklenmektedir. Bununla birlikte iş birlikli problem çözme basamaklarını anlamaya ve yorumlamaya çalışması ile kavrama basamağına ve uygulamaya yönelik bir cevap vermesi beklenmektedir.

2. Soru: Akvaryum tasarımında ilk olarak ne yapılması gerektiğini söylersiniz?

a) "Bence bir plan yapalım ve ilk olarak soruyu anlayalım."

b) "Herkes kendisi bir çözüm yolu bulsun."

c) "Acaba bizden önce soruna çözüm bulan olur mu ki?"

d) "Siz çözüm yolu için ne derseniz benim için uygun olur." 
$\mathrm{Bu}$ soruda ise öğrencinin problem çözmek için bir strateji geliştirmesi ve ortak anlayış oluşturma ve sürmeye yönelik olarak cevap vermesi ve iş birlikli problem çözme aşamasında problemi anlama ve fikir sunma ile uygulamaya yönelik cevap vermesi beklenmektedir.

\section{Bulgular}

Bu bölümde başarı testinin geliştirilmesi sürecinde elde edilen bulgular sunulmaktadır.

\section{Testin Pilot Uygulamasına Dair Elde Edilen Bulgular}

İşbirlikli problem çözme başarı testinin uygulandığı örneklem grubu yüksek puan alan öğrencilerden düşük puan alan öğrencilere göre sıralanmıştır. \% 27'lik alt ve \% 27'lik üst grup olacak şekilde iki grup belirlenmiş̧ir. Üst grubun belirlenmesi aşamasında 100 öğrenciden puanı en yüksek olan 27 öğrencinin puanlarına bakılmıştır. Bu öğrencilerden 27. Sıradaki öğrencinin puanının 17 olduğu tespit edilmiştir. 17 puan alan ilk 33 öğrenci \%27 lik grupta yer almıştır. Alt grupta ise \%27 lik grupta 8 puan alan 28 öğrenci olduğu görülmüştür ve grup sayısı 28 olarak belirlenmiştir.

Elde edilen veriler doğrultusunda maddeden oluşan başarı testinin her bir maddesinin ayırt edicilik ve madde güçlüğü değerleri Tablo 4'de sunulmuştur.

Tablo 4. Pilot Uygulama Kapsamın Alt ve Üst Gruplardaki Öğrencilerin Cevaplarına Göre Madde Analizi

\begin{tabular}{|c|c|c|c|c|c|}
\hline Soru No & Dü & $\mathrm{Da}$ & $\mathrm{p}$ & $\mathrm{r}$ & Sonuç \\
\hline 1 & 33 & 09 & 0,68 & 0,78 & Çok iyi \\
\hline 2 & 32 & 16 & 0,81 & 0,52 & Çok iyi \\
\hline 3 & 30 & 08 & 0,66 & 0,72 & Çok iyi \\
\hline 4 & 23 & 05 & 0,47 & 0,59 & Çok iyi \\
\hline 5 & 26 & 14 & 0,68 & 0,39 & İyi \\
\hline 6 & 14 & 03 & 0,20 & 0,36 & İyi \\
\hline 7 & 16 & 03 & 0,27 & 0,42 & Çok iyi \\
\hline 8 & 30 & 11 & 0,74 & 0,62 & Çok iyi \\
\hline 9 & 32 & 10 & 0,66 & 0,72 & Çok iyi \\
\hline 10 & 32 & 04 & 0,70 & 0,91 & Çok iyi \\
\hline 11 & 31 & 10 & 0,68 & 0,68 & Çok iyi \\
\hline 12 & 06 & 03 & 0,17 & 0,09 & Zayıf \\
\hline 13 & 33 & 10 & 0,77 & 0,75 & Çok iyi \\
\hline 14 & 29 & 07 & 0,58 & 0,72 & Çok iyi \\
\hline 15 & 27 & 07 & 0,56 & 0,65 & Çok iyi \\
\hline 16 & 28 & 06 & 0,55 & 0,72 & Çok iyi \\
\hline 17 & 28 & 10 & 0,53 & 0,59 & Çok iyi \\
\hline 18 & 32 & 11 & 0,68 & 0,68 & Çok iyi \\
\hline 19 & 33 & 08 & 0,65 & 0,81 & Çok iyi \\
\hline 20 & 28 & 07 & 0,65 & 0,68 & Çok iyi \\
\hline 21 & 21 & 09 & 0,46 & 0,39 & İyi \\
\hline 22 & 23 & 10 & 0,53 & 0,42 & Çok iyi \\
\hline
\end{tabular}

Tablo 4'de iş birlikli problem çözme başarı testi pilot uygulaması doğrultusunda her bir maddenin alt ve üst gruplarda yer alan ayırt edicilikleri ve madde güçlük indeksleri ile doğru cevap sayıları verilmiştir. Literatürde madde ayırt edicilik indeksi 0.40 ve üzeri oldukça iyi, $0.30-0.39$ arası makul seviyede iyi olarak değerlendirilmektedir. 0.20-0.29 arası ise düşük değerde/ geliştirilebilir ve 0.19 veya daha azı ise zayıf (çıkarılması gereken) madde olarak nitelendirilmektedir (Taib ve 
Yusoff, 2014; Rahim, 2010; Ebel veFrisbie, 1991; Escudero, Reyna ve Morales, 2000). Bu değerlere göre 1, 2, 3, 4, 7, 8, 9, 10, 11, 13, 14, 15, 16, 17, 18, 19, 20, 22 numaralı maddelerin oldukça iyi; 5, 6, 21 numaralı maddelerin iyi, 12 numaralı maddenin ise 0,09 zayıf madde olduğu görülmektedir. $\mathrm{Bu}$ bağlamda bu maddenin zayıf ayırt ediciliğe sahip olması nedeniyle testten çıkarılması kararlaştırılmıştır. Ayrıca bu maddenin madde güçlük indeksinin ise 0,17 olduğu görülmektedir. $\mathrm{Bu}$ madde $0.20^{\prime}$ dan daha düşük olduğu için testten çıkarılmıştır. Literatürde 0.20' dan düşük madde güçlük indeksinin zor bir madde olduğu belirtilmektedir. Ayrıca 0.21 ile 0.69 arasındaki madde güçlük indeksinin orta düzeyde zor olduğu, 0.7 - 0.9 arasındaki madde güçlük indeksinin kolay olduğu ve $>0.9$ 'dan büyük madde güçlük indeksinin oldukça kolay olduğu belirtilmektedir (Abdulghani, Ahmad, Ponnamperuma, Khalil ve Aldrees, 2014). Testin ortalama güçlügü ise 0.581 ortalama ayırt ediciliği 0.60 ve olarak belirlenmiştir. Bu bağlamda bu çalışmada elde edilen elde edilen güçlüğün orta düzeyde olduğu görülmektedir. Alan yazında yapılan çalışmalarda da testin ortalama güçlülüğünün 0,50 civarında olmasının istenen bir durum olduğu, testin çok kolay ya da çok zor olamaması gerektiği belirtilmektedir (Escudero, Reyna ve Morales, 2000; Quaigrain ve Arhin, 2017; Odukoya, Adekeye, Igbinoba ve Afolabi, 2018; Lane, Raymond ve Haladyna, 2015).

Bir testin güvenirlik katsayısının 1'e yaklaşması testin güvenirliğinin arttığını, 0'a yaklaşması güvenirliğin azaldığını ifade etmektedir (Gliem ve Gliem, 2003; Russek, 2004; Vansickle, 2015; Flateby, 2014). Testin güvenirlik katsayısının $0.60 \leq \alpha<0.80$ (Christiansen, 2014) değerleri arasında olması testin güvenilir olduğunu göstermektedir. Bu bağlamda iş birlikli problem çözme başarı testinin KR20 değeri 0,741 ve KR21 değerleri 0,720 olarak tespit edilen değerler kapsamında çalılmanın madde güçlükleri farklı olduğu için KR20 değeri dikkate alınmıştır ve çalışmanın güvenilir olduğu görülmektedir.

\section{Sonuç ve Tartışma}

$\mathrm{Bu}$ çalışmada dördüncü sınıf öğrencilerinin iş birlikli problem çözme becerisine yönelik bir başarı testi geliştirmek amaçlanmıştır. İş birlikli problem çözme öğrencilerin birlikte çaba göstererek problem durumunu çözme sürecini ifade etmektedir. İşbirlikli problem çözme sürecinde öğrenciler iş birlikli gruplar halinde tamamlamaya çalıştıkları görevde grup arkadaşlarının da desteği ile birlikte çalışmanın önemini anlamaktadır (Standl, 2016).

$\mathrm{Bu}$ çalışmada kapsam geçerliği için öncelikle kazanımlar tespit edilmiş ve bu kazanımlar uzman görüşüne sunulmuştur. Kazanımların iş birlikli problem çözme becerisinin temel kazanımları olmasına özen gösterilmiştir. Daha sonra bu kazanımların ölçülmesine uygun olarak test soruları hazırlanmıştır. Ayrıca hazırlanan belirtke tablosu ile hangi soruların hangi kazanımlara denk geldiği ve hangi bilişsel basamakla uyumlu olduğu belirtilmiştir. Bununla birlikte başarı testleri öğrencilerin ne bilip ne bilmediklerini ölçerek, konu ile ilgili herhangi bir yanılgıları varsa bu yanılgılar hakkında da bilgi vermektedir. Çoktan seçmeli testler ayrıca en fazla tercih edilen ölçme ve değerlendirme aracı olarak kullanılmaktadır (Akbulut ve Çepni, 2013).

Başarı testinin uygulaması 4. sınıfta öğrenim gören 100 öğrenci ile gerçekleştirilmiştir. İş̧ birlikli problem çözme başarı testinin maddeleri için madde analizi yapılmış ve ayırt edicilik ve güçlük indeksi hesaplanmıştır. Madde analizi ile bir madde testten çıkarılmış ve 21 maddeden oluşan dört seçenekli test son halini almıştır. Testin ortalama güçlügü 0.581 ortalama ayırt ediciliği 0.60 ve olarak belirlenmiştir. Testin KR20 değeri 0,741 olarak tespit edilmiştir. Sonuç olarak iş birlikli problem çözme becerisine yönelik dört seçenekli çoktan seçmeli sorulardan oluşan bir başarı testi geliştirilmiştir.

Hazırlanan başarı testi ile öğrencilerin iş birlikli problem çözme düzeylerinin belirlenmesi, iş birlikli problem çözme becerilerinin ölçülmesi hedeflenmiştir. Bu başarı testi ile öğrencilerin iş birlikli problem çözme becerilerinin değerlendirilmesi varsa tespit edilen eksikliklerin giderilmesi amaçlanmaktadır. 
Başarı testinin hazırlanmasında sorulan test maddelerinin ve programın doğrudan birbiriyle ilişkili olması gerekmektedir. Bununla birlikte bir başarı testi o gününü eğitim ihtiyaçlarına uygun olmalıdır (Shoemaker, 1975). Bu bağlamda hazırlanan iş birlikli problem çözme başarı testi günümüz eğitim ortamında son dönemlerde önemli bir yer tutmaya başlayan, PISA (2015) sınavlarında da bir değerlendirme kriteri olarak kullanılan iş birlikli problem çözme becerisini ölçmek amacıyla hazırlanmıştır.

Planlama ve hazırlık sürecinde başarı testinin adımlar net olarak belirlenmesi ve dikkatle her aşama gözden geçirilmelidir. Ancak bu sayede başarı testi özellikle belirli bir içerik kapsamında az ilerleme gösteren ya da yeterli beceriye sahip olmayan öğrencilerin belirlenmesine ve eksikliklerin giderilmesine yardımcı olabilecek bir başarı testi hazırlanabilir (Katz ve Slomka, 2000). Hazırlanan iş birlikli problem çözme başarı testi belirlenen aşamalar takip edilerek hazırlanmıştır.

Literatürde yapılan çalışmalar incelendiğinde öğrencilerin grup içinde çalışmalarının kontrol listesi şeklinde değerlendirildiği çalışmalara rastlanmaktadır (Avc1 Yücel, 2013; Law ve Wong, 2003). Bu şekilde yapılan değerlendirmenin gözleme dayanması, öğrencinin grup içinde arkadaşına verdiği tepkilerin dışardan gözlemle takip edilmesi söz konusu olabilir. Değerlendirmenin izlenerek yapılması öğrencinin tepkisini değiştirmesine ve gözlemin onu etkilemesine neden olabilir. Ancak verilen bir senaryoda "siz ne dersiniz" şeklinde sorulan bir soruya öğrencinin cevap vermesi, alternatifleri görmesi, gözlemlenmenin oluşturabileceği etkiyi aza indiren bir unsur olabilir. Öğrenci seçenekler arasından kendisine uygun olanı daha serbest bir şekilde seçebilir.

İş birlikli ortamda bir başka değerlendirme kriteri ise grup içinde öğrencilerin birbirlerini değerlendirmelerine yönelik yaptıkları akran değerlendirmesidir (Gömleksiz ve Koç, 2011; Yurdabakan ve Olğun, 2011). Akran değerlendirme sürecinde öğrenci grup içinde kişisel nedenlere bağlı olarak, grup arkadaşını objektif olarak değerlendirmekten çekinebilir. Yakın arkadaşına düşük bir not vermek istemeyebilir. Yaşının gereği olarak yaşadığı bir sorunu arkadaşını değerlendirme kriterinde dikkate alabilir. Bu bağlamda iş birlikli grup içinde özellikle küçük yaş grububna yönelik akran değerlendirme uygulamları tarafsızlık açısından sorun oluşturabilir.

Literatürde grubu değerlendirmeye yönelik yapılan çalışmalarda (Griffin, 2017; Önder, 2012; Quarstein ve Peterson, 2001), ise bir bütün olarak değerlendirme yapılması söz konusu olabilir ancak bu noktada ise grupta hangi öğrencinin iş birlikli problem çözme sürecinde hangi açılardan sürece katkı sağladığının belirlenmesi zor olabilir. Ayrıca grupta yer alan baskın öğrenciler iş birlikli problem çözme sürecinde diğer öğrencilerin katkılarının fark edilmesini engelleyebilir (Heller ve Hollabaugh, 1992). Ayrı ayrı yapılacak bireysel değerlendirme bu ihtimale karşı bir önlem olarak değerlendirilebilir. İş birlikli problem çözme sürecinde her öğrenci kendi bireysel adımının sorumluluğunu almalıdır (Way, 2011). Bu sorumluluk değerlendirme sürecine de yansıtıldığı süreçte öğrencinin iş birlikli problem çözme becerisi ölçülebilir. Ancak bir bütün olarak değerlendirilmesi gruptaki tüm kararların sorumluluğunun ortak bir şekilde paylaşılması anlamına gelmektedir.

İş birlikli problem çözme sürecinde öğrencilerin başarı testi ile bireysel olarak değerlendirilmelerinin bir başka olumlu sonucu ise gruptaki her bir öğrencinin bireysel seçiminden memnun olmasının sağlanmasıdır. Bir bütün olarak yapılan değerlendirmede grup üyesi her ne kadar kendi memnuniyeti olmasa da grup arkadaşlarına uyum sağlamak ya da çoğunluğun kararına uymak adına onaylamadığı bir durumda kalabilir ancak iş birlikli problem çözmenin temelinde tüm grup üyelerini memnun edecek bir sonuca ulaşılmasını hedeflenir (Wooldridge ve Jennings, 1999). Eğer öğrenci bireysel olarak kendisine uygun seçeneği işaretlerse tüm grup seçtiği sonuçtan memnun olacak ve bu doğrultuda değerlendirilecektir.

İş birlikli problem çözme sürecinde grubun tüm üyelerinin eşit katılımlarının sağlanması bir başka temel unsurdur (Cohen, 1994; Stahl, 1994). Sağlanacak eşit katılım aynı şekilde değerlendirildiği sürece iş birlikli problem çözmenin ne kadar başarılı olduğu belirlenebilir. Grup 
üyelerinin bu nedenle bireysel olarak ayrı ayrı değerlendirilmesi daha sağlıklı bir sonuca ulaşılmasını sağlayabilir.

İş birlikli problem çözme bilgisayar destekli ortamda (human to human) gerçekleştirildiğinde (Rosen ve Tager, 2013; Sandi-Urena, Cooper, Gatlin, ve Bhattacharyya, 2011; Nouri, Anna, Fors ve Selander, 2017) öğrencinin grup arkadaşı bilgisayarda ona cevap veren onu yönlendiren bir unsur olarak yer almaktadır. Bu noktada ona hazır bir şekilde seçenekler sunularak ondan uygun olanı seçmesi istenir. PISA (2015) uygulamalarında da öğrenciler bilgisayar ortamında gruplar şeklinde çalışmaktadır. Ancak değerlendirme bireysel değerlendirmeye dayanmaktadır. Uluslarası başarı sınavlarında öğrencinin iş birlikli problem çözme becerisi karşısındaki ekranda sunulan seçeneklerden uygun olanı seçmesiyle gerçekleştrilmektedir. Dolayısıyla yüz yüze yapılan uygulamalarda da benzer şekilde bir testin uygulanması öğrencinin bireysel olarak değerlendirilmesi sürece önemli bir katkı sağlayacaktır. Tüm bu nedenlere bağlı olarak iş birlikli problem çözme becerisinin ölçülmesine yönelik hazırlanan bu başarı testi ile ögrencinin grup çalışması ortamında bireysel olarak değerlendirmesi sağlanacaktır.

Bu çalışmada hazırlanan iş birlikli problem çözme başarı testi dördüncü sınıf öğrencilerinin iş birlikli problem çözme becerilerini ölçmek için kullanılabilir. Farklı değişkenler kullanılarak öğrencilerin iş birlikli problem çözme becerileri incelenebilir. Üst sınıflara yönelik yapılacak çalışmalara, geliştirilebilecek başarı testlerine yönelik bir çalışma olarak değerlendirilebilir.

\section{Kaynakça}

Abdulghani, H. M., Ahmad, F., Ponnamperuma, G. G., Khalil, M. S. ve Aldrees, A. (2014). The relationship between non-functioning distractors and item difficulty of multiple choice questions: a descriptive analysis. Journal of Health Specialties, 2(4), 148.

Akbulut, H. İ. ve Çepni, S. (2013). Bir üniteye yönelik başarı testi nasıl geliştirilir?: ilköğretim 7. sınıf kuvvet ve hareket ünitesine yönelik bir çalışma. Amasya Üniversitesi Eğitim Fakültesi Dergisi, 2(1), 18-44.

Ashman, A. ve Gillies, R. (Eds.). (2003). Cooperative learning: The social and intellectual outcomes of learning in groups. London: Routledge.

Avc1 Yücel, Ü. (2013). Çevrimiçi işbirlikli öğrenme ortamlarında gerçekleşen bilgi yapılandırma süreçlerinde etkileşim ve katılım. (Yayınlanmamış doktora tezi). Hacettepe Üniversitesi, Fen Bilimleri Enstitüsü, Ankara.

Bejarano, Y. (1987). A cooperative small-group methodology in the language classroom. TESOL Quarterly, 21, 483-501.

Carlan, V., Rubin, R. ve Morgan, B. (2005). Cooperative learning, mathematical problem solving, and Latinos. International Journal for Mathematics Teaching and Learning. Retrieved from http://www. cimt. plymouth. ac. uk/journal/morgan. pdf on, 09, 2019.

Christiansen, B. (Ed.). (2014). Handbook of research on effective marketing in contemporary globalism. IGI Global.

Cohen, E. (1994). Designing Group Work: Strategies for the Heterogeneous Classroom. New York: Teachers College Press.

De Leeuw, E. D., Hox, J. ve Dillman, D. (2012). International handbook of survey methodology. USA: Routledge.

Deutsch, M. (1962). Cooperation and trust: Some theoretical notes. In M. R. Jones (Ed.), Nebraska Symposium on Motivation (pp. 275-319). Lincoln, NE: University of Nebraska Press. 
Ebel R.L. ve Frisbie, D.A.(1991). Essentials of educational measurement. 5th ed. Englewood Cliffs, New Jersey: Prentice-Hall Inc.

Escudero, E. B., Reyna, N. L. ve Morales, M. R. (2000). The level of difficulty and discrimination power of the basic knowledge and skills examination (EXHCOBA). Revista Electrónica de Investigación Educativa, 2(1), 2.

Flateby, T. L. (2014). A guide for writing and improving achievement tests. Office of the Provost, University of South Florida, Tampa, FL Retrieved.

Ghaith, G. (2002). Using Cooperative Learning To Facilitate Alternative Assessment. In Forum (Vol. 40, No. 3, pp. 26-31). http://exchanges. state. gov/forum/.

Gillies, R. M. ve Haynes, M. (2011). Increasing explanatory behaviour, problem-solving, and reasoning within classes using cooperative group work. Instructional Science, 39(3), 349366.

Gliem, J. A. ve Gliem, R. R. (2003). Calculating, interpreting, and reporting Cronbach's alpha reliability coefficient for Likert-type scales. Midwest Research-to-Practice Conference in Adult, Continuing, and Community Education.

Gronlund, N. E. ve Linn, R. L. (2000). Measurement and assessment in education. UK: PrenticeHall International.

Gök, T. ve Sılay, İ. (2009). İşbirlikli problem çözme stratejileri öğretiminin öğrencilerin başarısı ve başarı güdüsü üzerindeki etklileri. Hasan Ali Yücel Eğitim Fakültesi Dergisi, 11(1), 13-27.

Gömleksiz, M. N. ve Koç, A. (2012). Bilgisayar kullanımı öğretiminde akran değerlendirme. Education Sciences, 7(1), 148-154.

Heller, P. ve Hollabaugh, M. (1992). Teaching Problem Solving Through Cooperative Grouping. Part 2: Designing Problems and Structuring Groups. American Journal of Physics, 60(7), 637-644.

Johnson, D. W., Skon, L. ve Johnson, R. (1980). Effects of cooperative, competitive, and individualistic conditions on children's problem-solving performance. American Educational Research Journal, 17(1), 83-93.

Johnston, J. H., Johnston, H.H. ve Markle, G. C. (1986). What research says to the middle level practitioner. Middle School Journal, 12(4), 22-24.

Katz, L. J. ve Slomka, G. T. (2000). Achievement testing. Handbook of psychological assessment, 149-182.

Lane, S., Raymond, M. R. ve Haladyna, T. M. (Eds.). (2015). Handbook of test development. Routledge.

Law, N. ve Wong, E. (2003). Developmental trajectory in knowledge building: An investigation. In Designing for change in networked learning environments (pp. 57-66). Dordrecht: Springer.

Heller, K. ve Heller, P. (2010). Cooperative problem solving in physics a user's manual. In Tersedia: http://www. aapt. org/Conferences/newfac ulty/upload/Coop-Problem-Solving-Guide. pdf.

Heller, P. ve Hollabaugh, M. (1992). Teaching problem solving through cooperative grouping. Part 2: Designing problems and structuring groups. American Journal of Physics, 60(7), 637-644. 
Odukoya, J. A., Adekeye, O., Igbinoba, A. O. ve Afolabi, A. (2018). Item analysis of universitywide multiple choice objective examinations: the experience of a Nigerian private university. Quality \& quantity, 52(3), 983-997.

Organisation for Economic Co-operation and Development (OECD). (2013). PISA 2015: Draft collaborative problem solving framework. OECD_2013_Collaborative\%20Problem\%20Solving\%20Framework.pdf adresinden 10.01.2019 tarihinde alınmıştır.

Önder, F. (2012). İşbirlikli gruplarda öğrenme stillerinin fizik dersi başarısı ile hatırda tutma düzeyine etkisinin incelenmesi. (Yayınlanmamış doktora tezi), Dokuz Eylül Üniversitesi, Eğitim Bilimleri Enstitüsü, İzmir.

Patton, M. Q. (1990). Qualitative evaluation and research methods. USA: SAGE Publications.

Russek, L. (2004). Factors affecting interpretation of reliability coefficients. Journal of Orthopaedic \& Sports Physical Therapy, 34(6), 341-349.

Quaigrain, K. ve Arhin, A. K. (2017). Using reliability and item analysis to evaluate a teacherdeveloped test in educational measurement and evaluation. Cogent Education, 4(1), 1301013.

Quarstein, V. A. ve Peterson, P. A. (2001). Assessment of cooperative learning: A goal-criterion approach. Innovative Higher Education, 26(1), 59-77.

Qin Z., Johnson D. W. ve Johnson R. T. (1995). Cooperative versus competitive efforts and problem solving. Review of Educational Research, 65(2), 129-143.

Rahim AFbA. What those number mean? 1st ed. Kubang Kerian: KKMED; 2010, Downloadable at: http://www.medic.usm.my/dme/images/stories/staff/KKMED/2010/item_analysis_guide.pd $\mathrm{f}$

Ramani, G. B. ve Brownell, C. A. (2014). Preschoolers' cooperative problem solving: Integrating play and problem solving. Journal of Early Childhood Research, 12(1), 92-108.

Rosen, Y. ve Tager, M. (2013). Computer-Based Assessment of Collaborative Problem-Solving Skills: Human-to-Agent Versus Human-to-Human Approach. Retrieved on June, 2, 2019.

Sandi-Urena, S., Cooper, M. M., Gatlin, T. A. ve Bhattacharyya, G. (2011). Students' Experience in a General Chemistry Cooperative Problem Based Laboratory. Chemistry Education Research and Practice, 12(4), 434-442.

Shoemaker, D. M. (1975). Toward a framework for achievement testing. Review of Educational Research, 45(1), 127-147.

Stahl, R. J. (1994). The Essential Elements of Cooperative Learning in the Classroom. ERIC Digest. Retrieved from https://files.eric.ed.gov/fulltext/ED370881.pdf.

Standl, B. (2016, April). A case study on cooperative problem solving processes in small 9th grade student groups. In Global Engineering Education Conference (EDUCON), 2016 IEEE (pp. 961-967). IEEE.

Szostek, C. (1994). Assessing the Effects of Cooperative Learning in an Honors Foreign Language Classroom. Foreign Language Annals, 27(2), 252-261. doi:10.1111/j.19449720.1994.tb01206.x

Şahin, Ç. ve Karakuş, G. (2019). Katılımcıları seçme: Evren ve örneklem. Gürbüz Ocak (Ed.) Ĕgitimde bilimsel araştırma yöntemleri içinde (s.179-216). Ankara: Pegem Akademi. 
Taib, F. ve Yusoff, M. S. B. (2014). Difficulty index, discrimination index, sensitivity and specificity of long case and multiple choice questions to predict medical students' examination performance. Journal of Taibah University Medical Sciences, 9(2), 110-114.

Tudge, J. R., Winterhoff, P. A. ve Hogan, D. M. (1996). The cognitive consequences of collaborative problem solving with and without feedback. Child development, 67(6), 2892-2909.

Yarrow, F. ve Topping, K. J. (2001). Collaborative writing: The effects of metacognitive prompting and structured peer interaction. British journal of educational psychology, 71(2), 261-282.

Yurdabakan, İ. ve Olğun, M. (2011). Öz ve akran değerlendirmenin ögrenme ve bilişüstü bilgi üzerindeki etkisi: Sonuçsal geçerlik. 2nd International Conference on New Trends in Education and Their Implications. 27-29 April, 2011 Antalya-Turkey.

Watson, S.B. (1992).The essential elements of cooperative learning. The American Biology Teacher, $54(2), 84-86$.

Way, J. (2011). Co-operative Problem Solving: Pieces of the Puzzle Approach Stage: 1, 2, 3 and 4. Retireved from https://nrich.maths.org/2547.

Vansickle, T. (2015). Test reliability indicates more than just consistency. Assessment Brief. April. 